\title{
Resenhas
}

http://dx.doi.org/10.5007/2175-7917.2020v25n2p222

\section{GILEAD ENTRE ESTÁTUAS E RUÍNAS: UMA RESENHA DE OS TESTAMENTOS, DE MARGARET ATWOOD}

\section{Gilead among statues and ruins: a review of Margaret Atwood's The Testaments}

\author{
Júlia Côrtes Rodrigues \\ https://orcid.org/0000-0001-5056-1875 \\ Universidade Estadual de Campinas, Programa de Pós-Graduação em Teoria e História \\ Literária, Campinas, SP, Brasil. 13083-859-cpgiel@iel.unicamp.br
}

ATWOOD, Margaret. Os testamentos. Trad. de Simone Campos. Rio de Janeiro: Rocco, 2019.

Os testamentos, de Margaret Atwood (2019), tem sido promovido no mundo todo como “O conto da aia 2". As obras possuem, é claro, forte elo temático que sustenta essa relação. Mas é curioso que o lançamento de 2019 seja popularmente chamado assim, pois foi publicado mais de trinta anos depois do celebrado $O$ conto da aia, publicado em 1985 - uma distância temporal atípica para uma sequência -. Atwood insistiu por muitos anos que não escreveria uma continuação para essa obra emblemática porque acreditava que a história da aia Offred já havia sido contada. Não haveria continuidade possível para essa voz. No romance de 2019, Atwood sustentou essa certeza: embora o romance mais recente seja efetivamente uma sequência, pois se passa aproximadamente quinze anos após o primeiro e mantém algumas de suas situações e personagens, a voz de Offred de fato se dissolveu. Agora acompanhamos três narradoras diferentes identificadas como "Hológrafo de Ardua Hall", "testemunha 369A", "testemunha 369B".

Em diversas resenhas de Os testamentos há uma menção ao "desafio" de Atwood. Afinal, O conto da aia (2017) se tornou peça, filme e série televisiva. O sucesso estrondoso do universo criado por Atwood fez da aia um símbolo (sua característica túnica vermelha foi adotada em diversos protestos feministas pelo mundo). Como escrever uma sequência para um romance que tem tanta força na história literária e na cultura política? "A onipresença cultural da aia

Esta obra está licenciada sob uma Creative Commons - Atribuição 4.0 
como uma abreviação da opressão feminina", afirma Kristen Roupenian, "teve o efeito contraintuitivo de domesticar o universo sombrio e bizarro que Atwood imaginara originalmente. O segundo livro simplesmente não consegue aterrissar com o mesmo choque de estranhamento do primeiro" (ROUPENIAN, 2019, n.p).

Esse desafio até pode abalar as expectativas dos leitores entusiasmados de $O$ conto da aia em relação à sequência. Pensar em Os testamentos como sua segunda parte com frequência o desfavoreceu. Porém, também é possível avaliar essa vitalidade da obra e sua sequência de forma positiva: afinal, se o romance de 1985 buscou provocar assuntos da ordem do dia, sua fama é um indício de que suas estratégias tiveram êxito. Nossa familiaridade com o universo de Gilead - ou o que Roupenian (2019) chama de "onipresença" - só é possível pela potência reflexiva de Atwood. Os testamentos não se limita às questões mais antigas que permanecem atuais, mas incluiu outras. No apêndice, Atwood (2019) revela que buscou responder aos anseios de seus ávidos leitores. Ou seja, a sequência não nasceu isolada da recepção da obra anterior. "Antes de se tornar palavras na página", a autora afirma,

Os testamentos foi escrito em parte nas cabeças dos leitores de seu antecessor, O conto da aia, que não paravam de perguntar o que tinha acontecido após o fim daquele romance. Trinta e cinco anos é um bom tempo para se pensar em respostas possíveis, e as respostas mudaram tanto quanto mudou a sociedade, e conforme possibilidades se tornaram realidades (ATWOOD, 2019, p. 575).

Atwood fornece muitas respostas sobre Gilead que Offred era incapaz de dar sozinha, por seu isolamento e pela época em que viveu. É oportuno refletir sobre a atualização do universo de Gilead no seio da discussão sobre o gênero speculative fiction, no qual a própria Atwood sempre se incluiu. "Se você fosse mesmo", pergunta Atwood, "enfiar as mulheres de volta em suas casas e privá-las de todas as conquistas, como isso aconteceria"? (ATWOOD, 2018, n.p). Assim, Atwood sustenta que o universo de $O$ conto da aia poderia muito bem ser visto como uma concretização extrema do que conservadores americanos estavam defendendo abertamente na mídia nos anos 1980. No século XXI, os desafios mudaram de configuração, mas não são menores. Em Os testamentos, cada uma das narradoras propicia uma olhar diverso sobre esse cenário. Combinados, eles nos dão uma espécie de panorama, ainda que fragmentado, do regime totalitário que se instaurou em solo americano. A começar pela pluralidade de narradoras, a sequência possui peculiaridades que surpreendem e asseguram sua singularidade na cena contemporânea.

É típica de Atwood a dualidade de suas personagens femininas. Como Sophie Gilbert (2019) resumiu brilhantemente, "as testemunhas que ela retrata em sua ficção não são salvadoras; elas são (ou esperam ser) sobreviventes, pessoas limitadas e comprometidas pelas circunstâncias, e que merecem ser ouvidas especialmente por esse motivo" (GILBERT, 2019, n.p). Esse ponto, aliás, parece crucial para localizar problemas de desenvolvimento da série televisiva inspirada em $O$ conto da aia. Numa polêmica resenha sobre a série, Fiona Sturges (2018) resume as escolhas problemáticas que surgiram na segunda temporada: "Mas na segunda fase, 'O conto da aia' arrancou toda a esperança, engoliu sua fúria, abandonou o comentário 
social e decaiu em uma crueldade cínica e sem sentido. Ela nos deixou como meros observadores, espiando estupidamente a carnificina" (STURGES, 2018, n.p). De fato, a produção passa a romantizar o sofrimento das aias e crianças de Gilead enquanto eleva a protagonista a uma posição de heroína incompatível com as circunstâncias repressoras do regime, pois seus atos grandiosos implicam em uma exposição de sua própria segurança e das companheiras que integram a resistência organizada. As personagens dos livros de Atwood, por sua vez, não carregam a mesma ambição. Como resume Steve Tully (2020), a ficção especulativa possui o expediente de "colocar pessoas comuns em circunstâncias extraordinárias" (TULLY, 2020, n.p): boa parte da verossimilhança do gênero se sustenta nesse aspecto, bem como sua capacidade de analisar, provocar e refletir sobre os valores de nosso tempo. É revigorante notar o quanto Os testamentos se negou, como Atwood (2019) disse que se negaria, a ser uma versão escrita da série de tevê.

De volta ao livro, a autora do hológrafo, descobrimos, é Tia Lydia, personagem que já havíamos conhecido em $O$ conto da aia. Aos olhos de Offred, Tia Lydia é uma espécie de personificação dos ideais de Gilead ou, como resumiu Gilbert, "menos uma pessoa e mais um gerador de slogans" (GILBERT, 2018, n.p). A tia cumprira papel fundamental na doutrinação forçada da narradora: Lydia era uma oradora segura, cujas falas propagandísticas não paravam de ressoar aos ouvidos de Offred, e também uma figura autoritária, que inspirava medo nas primeiras moças sequestradas para servirem como aias. Em Os testamentos, porém, a personagem de Lydia ganha complexidade agora que fala por si mesma. Descobrimos que, na verdade, ela apenas sustenta sua posição de chefe das tias porque é uma notável leitora da personalidade alheia (e não uma ingênua devota que papagaia frases feitas). Lydia é capaz de perceber as fraquezas e as ambições dos que estão ao seu redor e, assim, utiliza todas as informações que consegue a seu favor. Às vezes, inclusive, acoberta delitos alheios quando a exposição do corrupto não lhe convém. Não faltam falsos testemunhos, provas forjadas, abusos de poder, adultérios, assédios, estupros e assassinatos nos arquivos de Lydia.

A testemunha 369A é também uma voz interna a Gilead, mas trata-se de uma jovem de classe alta que cresceu lá. Mesmo sendo uma garota bem-comportada na maior parte do tempo, Agnes Jemima tem dificuldade em se conformar às expectativas sociais para ela, ou seja, a obediência aos pais e o casamento. A testemunha 369B, por sua vez, é Daisy, uma jovem canadense que atravessa crises típicas de uma adolescente contemporânea. Enquanto Agnes fala na maior parte do tempo de sua escola rigorosa e da rotina doméstica, Daisy reflete sobre sua identidade e flerta com ativismo anti-Gilead. Os acontecimentos do núcleo canadense evoluem com bastante rapidez, os demais personagens são esquemáticos e, como um todo, os desdobramentos lembram filmes de ação. Para Maureen Corrigan (2019), o romance se sustenta nessa tensão, que ela associa ao suspense. A alternância do sarcasmo de Tia Lydia com a pacata rotina de Agnes e a rebeldia de Daisy torna Os testamentos uma leitura mais ágil do que $O$ conto da aia.

Embora seja um romance que permite uma leitura bastante fluida, Os testamentos também pode ser apreciado em minúcias - e nisso se assemelha a seu irmão mais velho, O conto da aia 
-, em alguns de seus melhores momentos. Certas passagens asseguram que a sagacidade de Atwood não se perdeu pelas décadas. Por exemplo, um detalhe engraçado (com todo seu brilhantismo e acidez) é o nome do café frequentado pelas tias: Café Schlafly, uma referência à intelectual cristã e conservadora Phyllis Schlafly, ícone do antifeminismo. Atwood, assim, sugere provocativamente que Schlafly teria sido uma heroína para os fundadores de Gilead. Schlafly, entre outras coisas, era contrária à equidade de direitos civis para casais hetero e homossexuais (ela achava que gays não poderiam adotar e educar uma criança, por exemplo). A presença do nome de Schlafly em Os testamentos opera também como uma espécie de resíduo das reações intensas dos anos 1980 contra diversas correntes do feminismo que emergiram na década anterior: um resíduo das questões que Atwood buscou responder em $O$ conto da aia, com inteligência, invenção e humor.

O sarcasmo de Atwood se faz presente em Os testamentos em diversas situações, incluindo em sua conhecida propensão de satirizar acadêmicos. Uma passagem divertida também se manifesta no relato de Agnes, aconselhada a considerar um pretendente com muita cautela porque ele tinha o inconveniente defeito de ser um leitor: "Ele era bom com números, disse Tia Gabbana, e era intelectual, nem sempre algo desejável - especialmente não para mulheres -, mas em um marido, isso poderia ser tolerado.” (ATWOOD, 2019, p. 301).

A sátira aos estudiosos é também elemento chave nas conferências fictícias que encerram O conto da aia e Os testamentos. O segundo livro apresenta suas narradoras como fontes, seus textos como documentos. No apêndice, a frieza com que os intelectuais tratam seus objetos contrasta muito com a intensidade que testemunhamos ao longo dos romances - e, de certa forma, com as estratégias do romance especulativo -. O final do hológrafo de Lydia é cruel e brilhante nesse sentido. Ela se dirige a uma leitora imaginária, uma moça inteligente e com ambições acadêmicas: "Você vai labutar nesse meu manuscrito, lendo e relendo, procurando pelo em ovo à medida que avança, desenvolvendo o ódio fascinado, mas também entediado, que biógrafos tantas vezes chegam a sentir por seus biografados" (ATWOOD, 2019, p. 555). Atravessa o hológrafo uma preocupação em contextualizar essas tomadas de decisão. $\mathrm{O}$ testamento preserva um fragmento da consciência de Lydia que não poderíamos acessar de outra forma. No começo do romance, a personagem rejeita uma estátua forjada à sua semelhança, a qual literalmente a petrifica numa homenagem vazia. Lydia não confia nas honrarias e no testemunho de outros habitantes de Gilead, pois não quer se confinar ao esquematismo de sua imagem pública, que já conhecíamos pelo olhar de Offred.

Essas minúcias das personagens passam quase que despercebidas nas conferências acadêmicas dos romances, frequentadas pelos estudiosos ficcionais que tanto se debruçaram sobre os manuscritos, como Lydia prevera, com pressa e ambição. Mas esses congressos não somente servem ao intuito de satirizar a cega objetividade dos estudiosos, mas de colocar também os eventos do romance em perspectiva histórica. Por sua combinação de práticas arcaicas com uma hecatombe futurista, pode ser ardiloso localizar e compreender Gilead. Ao mesmo tempo, quando aborda Gilead num futuro distante, já como uma sociedade falida e extinta, a própria autora de alguma forma leva a cabo uma revanche ao sistema - inclusive 
porque acaba com ele por dentro. Os testamentos foi muito considerado, com razão, um livro mais leve e otimista que $O$ conto $d a$ aia. "Se pareço levemente decepcionada com $O s$ testamentos é porque, paradoxalmente a novela gentilmente (talvez com facilidade demais) me dê o que eu mais quero: a promessa de um fim de Gilead)", resume Corrigan (2019, n.p). Os testamentos nos propõe uma imersão no que Gilead tem de mais violento e mais quebradiço, passamos tanto por suas estátuas e monumentos quanto por suas hipocrisias e ruínas.

O tom cômico ajuda a suspender uma lição moralizante, mas existe uma certa pedagogia que permeia a escrita de Atwood. Uma curta definição de ficção especulativa parece propícia também para pensar sua contribuição: "A ficção especulativa", afirma Tom Wagner, "é um itinerário do amanhã e uma bíblia para o além" (2020, n.p). Através das conferências, Atwood nos sugere, também, um aprendizado possível. "Vocês têm perguntas?" é a famosa última frase de $O$ conto da aia. O irônico é que o pesquisador que se oferece para responder nossas perguntas apenas pode fazê-lo de forma burocrática e sem imaginação. Lydia encerra seu hológrafo com uma provocação a uma leitora imaginária, pretensiosa e dedicada: “Como é que eu pude ser tão má, tão cruel, tão burra?, você vai se perguntar. Você pessoalmente nunca teria feito as coisas daquele jeito! Mas você pessoalmente nunca precisou fazê-las" (ATWOOD, 2019, p. 556). Por meio da leitura atenta da obra de Atwood e de uma certa sensibilidade, podemos nos perguntar não apenas o que teríamos feito naquelas situações, mas o que pode ser feito em nosso tempo repleto de lampejos dessa pavorosa distopia.

\section{Referências}

ATWOOD, Margaret. O conto da aia. Trad. de Ana Deiró. Rio de Janeiro: Rocco, 2017.

ATWOOD, Margaret. Os testamentos. Trad. de Simone Campos. Rio de Janeiro: Rocco, 2019.

CORRIGAN, Maureen. Atwood Hints At A Brighter Future In 'Handmaid' Sequel 'The Testaments'. NPR, 92 set. 2019. Disponível em: https://www.npr.org/2019/09/09/759040269/atwood-hints-at-a-brighter-future-in-handmaidsequel-the-testaments. Acesso em: 11 jul. 2020.

GILBERT, Sophie. The challenge of Margaret Atwood. The Atlantic, 5 set. 2019. Disponível em: https://www.theatlantic.com/entertainment/archive/2019/09/margaret-atwood-handmaidstale-sequel-the-testaments/597385/. Acesso em: 10 jul. 2020

MARGARET Atwood: The Handmaid's Tale is being read very differently now. Vídeo postado no youtube. Vintage Books. 2018. 10min58. Disponível em: https://www.youtube.com/watch?v=7a8LnKCzsBw. Acesso em: 9 jul. 2020.

ROUPENIAN, Kristen. The Uneasy Uplift of The Testaments. The New Republic, 5 dez. 2019. Disponível em https://newrepublic.com/article/155690/uneasy-uplift-margaret-atwoodtestaments-book-review. Acesso em: 11 jun. 2020

STURGES, Fiona. Why I've stopped watching The Handmaid's Tale. The Guardian, 16 jun. 2018. Disponível em: https://www.theguardian.com/tv-and-radio/2018/jun/16/handmaids-taleseason-2-elisabeth-moss-margaret-atwood. Acesso em: 10 jun. 2020 
TULLY, Steve. What is speculative fiction?. ANTHOLOGY of Speculative Fiction. Free Speculative Fiction Online. Berlin: 2020, n.p. v. 1. Disponível em: https://www.freesfonline.net/Magazines.html. Acesso em: 11 jul. 2020.

WAGNER, Tom. What is speculative fiction?. ANTHOLOGY of Speculative Fiction. Free Speculative Fiction Online. Berlin: 2020, n.p. v. 1. Disponível em: https://www.freesfonline.net/Magazines.html. Acesso em: 11 jul. 2020.

\section{NOTAS DE AUTORIA}

Júlia Côrtes Rodrigues (juliacortesrodrigues@gmail.com) atualmente é estudante de doutorado do Programa de Pós-Graduação em Teoria e História Literária na Universidade Estadual de Campinas. Desenvolveu pesquisa de mestrado no mesmo Programa. Possui graduação em Licenciatura em Língua Portuguesa e Bacharelado em Estudos Literários pela Universidade Federal de Ouro Preto. Tem experiência como docente de inglês e tradutora de textos gerais e literários. São suas áreas de interesse e atuação: teoria literária, textos poéticos, ensino de língua estrangeira, tradução, tradução literária.

\section{Como citar esse artigo de acordo com as normas da revista}

RODRIGUES, Júlia. Gilead entre estátuas e ruínas: uma resenha de Os testamentos, de Margaret Atwood. Anuário de Literatura, Florianópolis, v. 25, n. 2, p. 222-227, 2020.

\section{Contribuição de autoria}

Não se aplica.

\section{Financiamento}

Conselho Nacional de Desenvolvimento Científico e Tecnológico - CNPq.

\section{Consentimento de uso de imagem}

Não se aplica.

\section{Aprovação de comitê de ética em pesquisa}

Não se aplica.

\section{Licença de uso}

Este artigo está licenciado sob a Licença Creative Commons CC-BY. Com essa licença você pode compartilhar, adaptar, criar para qualquer fim, desde que atribua a autoria da obra.

\section{Histórico}

Recebido em: 28/05/2020

Revisões requeridas em: 06/07/2020

Aprovado em: 20/07/2020

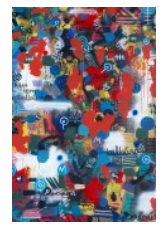

